\title{
Bordwell, Bazin y la ilusión cinematográfica El sueño de Zavattini como la pesadilla de Bordwell
}

\author{
Alberto J. L. Carrillo Canán \\ Benemérita Universidad Autónoma de Puebla (México) \\ acarrillo mx@yahoo.com
}

Recibido 2/07/2016

Aprobado 27/08/2016

\section{Resumen}

Sin duda alguna David Bordwell es el teórico de cine más influyente en la actualidad en el medio anglosajón; su teoría cognitiva de la narración cinematográfica tiene importantes virtudes que en dicho medio la llevaron a desbancar a teorías rivales como la semiótica, la psicológica y la marxista. Por su base cognitivista la teoría de Bordwell tiene una importante tendencia empírica y especialmente hace hincapié en la continuidad entre las operaciones perceptivas y cognitivas en la vida real y en el cine narrativo. Sin embargo, justamente esta virtud cognitivista, que es la fuerza de la teoría de Bordwell, tiene la desventaja de dejar de lado fenómenos y categorías específicamente estéticos. Podríamos decir que la teoría cognitiva de Bordwell es una naturalización de la teoría del cine en la que la dimensión estética del fenómeno fílmico queda fuertemente desatendida. En particular el fenómeno de la ilusión tecnológica cinematográfica en tanto experiencia estética desaparece por completo del marco teórico; con el objetivo de rescatar este fenómeno, central en la experiencia cinematográfica, en este trabajo nos apoyamos en la teoría cinematográfica de Bazin y confrontándola con la de Bordwell demostramos que la muy conocida práctica del montaje o edición es lo que sirve a Bordwell para, sin decirlo, eliminar por completo de su teoría el fenómeno estético de la ilusión, mientras que, al contrario, en Bazin la crítica del montaje va de la mano con una aguda conciencia del fenómeno de la ilusión específicamente cinematográfica. En 
particular subrayamos la tesis de Bazin de que si se deja fuera de consideración el fenómeno de la ilusión, la experiencia fílmica queda homologada en gran parte a la meramente literaria.

Palabras clave: mímesis, registro, ilusión, edición, causalidad, imaginación.

\section{Abstract}

Undoubtedly, David Bordwell is by now the most important English-speaking film theoretician and his cognitive theory of narrative film has important advantages that allowed it to oust rival film theories such as the semiotic, the psychological, and the Marxist ones. Due to its cognitivist foundations, Bordwell's theory has a strong empirical tendency and it emphasizes the continuity between the perceptual and cognitive operations in real life and in narrative cinema. Yet, just the cognitivist character of the theory has the negative effect of letting out of the picture properly aesthetic phenomena and categories. It is possible to say that Bordwell's theory is a naturalization of film theory by virtue of which the aesthetic dimension of cinema practically disappears from the theoretical consideration. Particularly, the phenomenon of the cinematographic technological illusion as aesthetical experience results completely eliminated from the theory. In order to recover such phenomenon, which is basic for the cinematographic experience, in this text we resort to Bazin's film theory and contrast it with Bordwell's theory and we show that Bordwell refers to the well-known practice of editing for completely letting out of his theoretical frame the aesthetical phenomenon of illusion, whereas, on the contrary, Bazin's criticism of editing goes hand in hand with a keen awareness of the phenomenon of the specifically cinematographic illusion. Particularly, we emphasize Bezin thesis that letting out of consideration the phenomenon of the cinematographic illusion leads to reducing the filmic experience to the merely literary one. Keywords: mimesis, record, illusion, edition, causality, imagination. 
“(...) [E]n su imaginación (...) vieron en un instante (...) una ilusión perfecta del mundo exterior en sonido, color y relieve." Bazin, refiriéndose a los precursores tecnológicos del cine.

"Permítasenos concordar en que el cine debería de ofrecer al espectador una ilusión tan perfecta de la realidad como sea posible dentro de (...) los límites actuales de la técnica." Bazin

“Las teorías miméticas conciben la narración como la presentación de un espectáculo, como un mostrar." Bordwell

David Bordwell abre su texto ya clásico Narration in the Fiction Film (1985) sometiendo a intensa crítica lo que él llama las "teorías miméticas de la narración", crítica que constituye el primer capítulo de su famosa obra. En el centro de la crítica de Bordwell a la idea de las imágenes fílmicas como mímesis está el hecho prácticamente universal de la edición cinematográfica. Bordwell señala que un filme no registra ninguna historia que ocurra delante de la cámara porque, digamos, a diferencia de lo que sucede en el teatro, donde hay una realidad - una "historia" - que se desarrolla fluidamente delante de la audiencia, en el cine no hay realmente ninguna realidad que se desarrolle fluidamente delante de la cámara para que, después, tal desarrollo fluido sea contemplado por la audiencia cinematográfica. Por el contrario, Bazin, como el gran teórico del realismo y la ilusión cinematográficos, valora en alto grado el desarrollo fluido de una realidad delante de la cámara. Ciertamente, para Bazin tal desarrollo fluido de una realidad delante de la cámara no es el único elemento del realismo cinematográfico pero es su principal característica mediática, es decir, fílmica y, como tal, indispensable, necesario. Más aún, lo que podemos llamar la ilusión cinematográfica realista - hay otros tipos de ilusión cinematográfica -, depende básicamente del desarrollo fluido de una realidad frente a la cámara, idea que Bazin llega, incluso, a declarar como una "ley estética". En este texto 
examinaremos las posiciones de Bordwell y Bazin con el objetivo de rescatar la tesis de Bazin acerca de la importancia del cine como medio privilegiado de la ilusión, fenómeno, el de la ilusión, que la polémica de Bordwell contra las "teorías miméticas" elimina por completo del marco teórico. En Bordwell no hay espacio para pensar siquiera el problema de la ilusión cinematográfica, sea esta realista o no. Por nuestra parte queremos rescatar, contra la influyente teoría narrativa del cine elaborada por Bordwell, la tesis de Bazin del cine como generador de ilusión.

\section{La "información", la descripción del plano fílmico y la mímesis}

Resulta útil formalizar algunas ideas básicas de Bordwell para poder discutir su tesis negativa respecto de la mímesis en el cine, es decir, su rechazo de que el cine, sea, en algún modo, mímesis. Siguiendo la teoría literaria del formalismo ruso, ${ }^{1}$ Bordwell utiliza los conceptos de "fábula", o historia, y de "syuzhet", o trama, conceptos puramente literarios, a los que él añade un tercero, el de "estilo", el cual sería necesario justamente por la naturaleza tecnológica que constituye el medio cinematográfico a diferencia de la literatura. ${ }^{2}$ Dado este marco conceptual, Bordwell considera dos conjuntos de relaciones, ${ }^{3}$ por un lado, la relación típicamente tratada por la teoría literaria, entre la "trama" y la "historia", relación que es un asunto totalmente independiente del medio cinematográfico y, por otro lado, Bordwell considera, además, las relaciones entre el medio fílmico en sus características tecnológicas, es decir, el "estilo", y la "trama". La formalización que nos interesa para clarificar estos dos conjuntos de relaciones, de tal manera que podamos rescatar el concepto de mímesis, consiste en substituir el término de Bordwell "información" - un término muy apropiado para la aproximación cognitivista de Bordwell al cine como medio narrativo - por el concepto de "proposición". Expliquémonos.

Bordwell señala con toda la claridad deseable, para nuestros fines, que "[e]n términos lógicos el patrón del syuzhet es independiente del medio; los mismos patrones

\footnotetext{
${ }^{1}$ BORDWELL, David. Narrative in the Fiction Film. Madison, University of Wisconsin Press, 1985, p. 49.

${ }^{2}$ Bordwell: "El syuzhet corporifica la película como proceso 'dramatúrgico'; el estilo la corporifica como un proceso 'técnico'." (Ibid., 55)

${ }^{3}$ Ibid., 50
} 
del syuzhet [trama] podrían ser corporificados en una novela, una representación teatral o una película (...)", 4 en otras palabras y como era de esperarse, dado que los conceptos de "trama" (syuzhet) y de "fábula" (historia), vienen de la teoría literaria propiamente dicha, ambos conceptos se refieren a una dimensión puramente conceptual, al margen de cualquier medio sensorial, ya sea este pictórico, teatral, fílmico, etc., es decir, el ámbito de tales conceptos es solo conceptual, totalmente independiente de las artes visuales figurativas (miméticas). Adicionalmente Bordwell cita a Tomashevsky diciendo que "[I]a fábula se distingue del syuzhet, el cual está constituido por los mismos eventos, pero el syuzhet respeta su orden en la obra [que no tiene que ser el mismo que en la fábula] y la serie de procesos de información que los designan [a los eventos]." ${ }^{5}$ Llevando la idea al medio fílmico, Bordwell nos dice que el syuzhet “(...) es el arreglo real y la presentación de la fábula en la película (...)", ${ }^{6}$ de manera análoga, solamente análoga, a como lo piensa Tomashevsky para la novela. En realidad esto remite a la clásica distinción narratológica de la que Bordwell no quiere saber nada - según lo señala en el capítulo 2 de su libro ${ }^{7}$ entre la "historia" (fábula o relato) y el "discurso", distinción que básicamente considera a la historia como lo que pasó - así sea real o ficticiamente - y al discurso como la manera en la que se cuenta, incluyendo privilegiadamente la "transformación" (Chatman) del orden de los eventos, por ejemplo del orden de ocurrencia, es decir, del orden en la historia, $A-B-C$ al orden den narración $C-A-B .^{8}$ El otro elemento importante en la cita

\footnotetext{
${ }^{4}$ Ibid., 55. En realidad, siguiendo la idea narratológica estándar - a la que nos referiremos abajo - de que la narrativa es independiente del medio que la porta, Bordwell se suma a dicho error. En este punto la narratología en su conjunto está equivocada de medio a medio. Por lo menos en el teatro tradicional, en la ópera, en el valet y la pantomima narrativa, es prácticamente imposible hacer permutaciones del orden temporal - un "patrón del zyushet" - ya sea retrospectivas o prospectivas, sin introducir un elemento verbal que lo clarifique, es decir, un elemento de carácter específicamente literario. Salvo en el cine y en la literatura las permutaciones temporales entre el orden de la trama y el orden de la historia, son prácticamente imposibles porque sin el elemento verbal, literario, ajeno al medio teatral, operístico, etc., el espectador no puede comprenderlas. Esto quedará más claro con ayuda del texto principal.

5 Ibid., 50.

${ }^{6}$ Ibidem.

${ }^{7}$ Ibid., 22-3.

${ }^{8}$ El teórico narratológico del cine Christian Metz llama a estas alteraciones del orden de los eventos una "permutación", mientras que Bordwell las llama un "barajado [reshuffling y shuffling]" (Ibid., 33, 77). Sobre esto véase Metz y Chatman (la referencia la doy más adelante); para una discusión sistemática véase CARRILLO CANÁN, Alberto. Fotografía, cine, juegos digitales y narratividad: estudios sobre la sensibilidad novomediática. México, BUAP \& Itaca, 2013, especialmente los ensayos 3 y 9. Por cierto, en el teatro
} 
de Tomashevsky es el término "información", o aquello a lo que ya antes Bordwell se había referido como "información narrativa". 9 Al estar hablando de literatura, obviamente, Tomashevsky no está pensando en nada sensorial sino en la "información" que da una trama literaria, pero Bordwell considera bajo su término "información" tanto al "estilo" en tanto dimensión sensorial de la película, como a la "trama", el syuzhet, en tanto su dimensión conceptual, por ello Bordwell nos habla de "estructuras de información - un sistema narrativo y un sistema estilístico (...)" ${ }^{10}$ Por supuesto, como parte del "sistema estilístico" de información tenemos de manera privilegiada a la "información visual"11 aportada por la película en tanto entidad fenoménica, es decir, experimentable sensorialmente. $^{12}$

Si el centro de las relaciones entre la fábula (historia) y el syuzhet (trama) está en lo que el narratólogo Metz llama la "permutación" de los eventos de la historia en su presentación en la obra a través del syuzhet (Tomashevsky), ${ }^{13}$ que es lo mismo que lo que Chatman llama la "transformación" del orden de la "historia" en su desarrollo en el "discurso", ${ }^{14}$ para Bordwell el centro de las relaciones entre el syuzhet y la historia es lo que él considera la "construcción de la historia". ${ }^{15}$ Ciertamente tanto la "permutación" de Metz como la "transformación" de la "historia" en "discurso" de Chatman conllevan una visión de la narración - ya sea fílmica o literaria - como algo terminado, realizado: se

tradicional, en la ópera, en la pantomima, el discurso, o en términos de Bordwell la trama, por un lado, y la historia, por otro, siempre coinciden: el orden de la presentación de los eventos es el mismo que el de su ocurrencia en la historia. Son medios que no pueden portar una historia basándose en un discurso "permutado" (Metz) o "transformado" (Chatman) temporalmente respecto de la historia. Véase el texto principal un poco adelante. Si Bordwell miso dice que “(...) la mayoría de las películas evita barajados temporales (...)" (Op. Cit. BORDWELL, David. Narrative in the Fiction Film. P. 33) porque el espectador puede confundirse con facilidad, eso es muchísimo más válido del teatro, la opera y la pantomima, por lo menos.

${ }^{9}$ Ibid., 25, 34.

${ }^{10}$ Ibid., 33.

${ }^{11}$ Ibid., 31, 32.

${ }^{12}$ Véase también: "datos visuales entrantes" (Ibid., 32). Por supuesto, la película en tanto entidad fenoménica, también porta sonidos ambientales y verbales, pero dado que esta dimensión acústica no aporta nada relevante para nuestra discusión, la dejamos de lado en lo fundamental. Solamente recordemos que Bordwell se refiere a una película como una "mezcla de estímulos visuales, auditivos y verbales" (Ibid., 33)

${ }^{13}$ Véase METZ, Christian. Film Language. A Semiotics of Cinema. Chicago, The University of Chicago Press, 1991, p. 37.

${ }^{14}$ Véase Chatman, Seymour. Story and Discourse. Narrative Structure in Fiction and Film. Ithaca \& London, Cornell University Press, 1978.

${ }^{15}$ Op. Cit. BORDWELL, David. Narrative in the Fiction Film. P. 34. 
compara la historia con la manera en la que se "contó" o se "presentó". Por el contrario, para Bordwell las relaciones entre el la syuzhet (discurso) y la fábula (historia) son las del proceso dinámico de "construcción de la historia" o fábula con base en la "información" dada por el syuzhet. ${ }^{16}$ Esto permite atisbar la importancia del concepto informal de "información" de Bordwell, informal porque Bordwell lo toma como una primitiva en su libro, como concepto de sentido común que en realidad no necesitaría de ninguna clarificación.

La "construcción de la historia" como condensación de las relaciones entre syuzhet e historia o fábula es un asunto que en este texto no nos incumbe por lo que solamente haremos algunas observaciones en los momentos en que sea necesario. Lo importante para nosotros ahora es avanzar hacia la formalización del concepto de "información" de Bordwell y para ello debemos considerar las relaciones entre el syuzhet y el "estilo", la dimensión sensorial de la película. De hecho el "estilo", que es la película misma en tanto entidad fenoménica, remite directamente a lo que Bordwell llama los "esquemas". Los "esquemas" nos servirán como un paso para la precisión del concepto de información.

El concepto de Bordwell de "esquemas" - que él toma de varios autores - es bastante amplio y hasta cierto punto indefinido, ${ }^{17}$ pero la primera de las ideas básicas de interés aquí es la de los "esquemas prototipo", ${ }^{18}$ los cuales “(...) parecen los más relevantes para identificar agentes individuales, acciones, metas y localidades." 19 Refiriendo a la película Bonnie and Clyde (1967) tendríamos los esquemas prototipo

\footnotetext{
${ }^{16}$ Véase Bordwell: "El capítulo tres [de su obra que nos ocupa] esboza una teoría de la actividad narrativa del espectador considerando la observación de una película como un proceso perceptivo cognitivo dinámico." (Ibid., xiii)

${ }^{17}$ La amplitud e indefinición del término "esquema" en Bordwell se aprecia, por ejemplo, cuando él mezcla lo que en filosofía se llama "contenidos mentales" con "estructura semántica", es decir, conceptuales, con "contenidos mentales" sin estructura semántica, lo que se suele llamar, por ejemplo, "imágenes mentales": "La imagen mental de un ave es un esquema para el reconocimiento visual y el concepto de una oración bien formada funciona como un esquema en la percepción del habla." (Ibid., 31) Bordwell también nos habla de "(...) esquemas que proponen los lugares para mirar más productivos (...)" (Ibid., 32) o bien de "(...) esquemas que generan hipótesis acerca de lo que veremos a continuación." (Ibidem), los cuales, estos últimos, deben ser considerados como "inferencias" que ocurren "de una manera involuntaria, virtualmente instantánea" (Ibid., 31) y, obviamente las inferencias son procesos conceptuales o lógicas, es decir estados mentales con "contenido semántico" - también llamado "contenido proposicional" -

${ }^{18}$ Ibid., 34.

${ }^{19}$ Ibidem.
} 
“amantes", "robo de banco", "pequeño pueblo sureño", "era de la gran depresión". ${ }^{20}$ Es claro que los dos primeros mencionados corresponden directamente a lo que se ve en un solo plano cinematográfico, si bien puede ser presentado en varios o sugerido por varios planos. En un solo plano queda definitivamente claro que un hombre y una mujer son amantes, también en un solo plano queda claro que ocurre un robo bancario, un solo plano deja en claro que se está en un pequeño pueblo sureño. A diferencia de lo anterior, el "esquema" "era de la gran depresión" requiere de varios planos que primero sugieren tal evento y luego lo confirman; en todos se ve algo que corresponde a la gran depresión, pero la gran depresión no es algo que se vea como ve uno amantes o el evento de un robo bancario. Por su parte el "esquema" "pequeño pueblo sureño" puede estar en una situación intermedia, ya que lo que se ve en un solo plano puede ser reconocido como un tal pueblo, pero también es posible que se requiera de varios planos para pensar en tal pueblo. En todos los casos hemos hablado de lo que se ve en un plano, es decir, de lo que se reconoce en él y, por tanto, se piensa, y además se puede describir si se expresa lo que se ve. ${ }^{21}$ Así por ejemplo, el "esquema" "amantes" corresponde a la proposición clasificatoria o descripción atómica "(esos) son amantes", el "esquema" "robo de banco" corresponde a la proposición clasificatoria o descripción atómica "(eso) es un robo de banco"; de la misma manera los "esquemas" "pequeño pueblo sureño" y "era de la gran depresión" corresponden a las proposiciones descriptivas "(eso) es un pequeño pueblo sureño" o "(eso) es la era de la gran depresión". Queda claro entonces que los solos predicados, las oraciones que en castellano no hacen explícito el sujeto, el "eso", son los "esquemas prototipo" de Bordwell, y lo importante es que o bien son descripciones directas de lo que se ve en los planos correspondientes o bien, como el caso de "era de la

\footnotetext{
${ }^{20}$ Ibidem.

${ }^{21}$ En lo sucesivo el ver será asimilado a lo que Dretske (Cfr. DRETSKE, Fred. Perception, Knowledge, and Belief. Cambridge, Cambridge University Press, 2000, pp. 97-112) llama, en oposición al "ver simple", "ver epistémico", que un pensar con base directa en lo que se ve, un pensar que puede ser expresado verbalmente por una descripción de lo que se ve. Nótese, entonces que el "ver" en este sentido es más que simplemente recibir información sensorial, es a) primero recibirla y luego b) recodificarla conceptualmente. Sobre este punto véase un poco más abajo el texto principal. De cualquier manera insistimos en que, a diferencia de Bordwell quién continuamente mezcla y confunde el ver con pensar, nosotros distinguimos claramente entre el ver como simple recepción de información sensorial y el ver conceptual, como recodificar la información sensorial en términos conceptuales, que es un ver ya intelectualizado.
} 
gran depresión", son predicados que engloban a descripciones de lo que se ve en varios planos, es decir, descripciones de situaciones típicas de lo que sabemos - pensamos - que fue la gran depresión. ${ }^{22}$ Llamaremos a los "esquemas prototipo" que corresponden a descripciones del contenido de los planos esquemas prototipo básico y esquemas prototipo derivados a aquellos que engloban a tales descripciones que corresponden a esquemas prototipo básicos. En realidad todos los planos con un contenido visual definido admiten de una o varias descripciones y, por lo tanto, corresponderían a uno o varios esquemas prototipo básicos.

Resulta conveniente señalar que los ejemplos de "esquemas prototipo" que hemos considerado corresponden a tres de los primeros que Bordwell menciona al decir que "(...) cualquier esquema para eventos [robo bancario], localidad [pequeño pueblo sureño], época [la gran depresión] y causa efecto, puede ser pertinente para darle sentido a una película narrativa." ${ }^{23}$ Sin embargo, en este fragmento apareció un tipo nuevo de esquema, el de "causa efecto" que tiene gran importancia en nuestro contexto.

De hecho, el "esquema" de causa efecto ya no es ningún "esquema prototipo", sino que pertenece a otra clase de esquemas que serían los "esquemas plantilla", ${ }^{24}$ los cuales satisfarían lo que Bordwell Ilama la "tendencia de los esquemas prototipo" a operar en una "estructura mayor". ${ }^{25}$ Bordwell menciona que tales "esquema plantilla", que permiten utilizar narrativamente los "esquemas prototipo", son de diferentes clases, entre los que están aquellos que atañen a la "causalidad lineal", ${ }^{26}$ justamente lo que Bordwell llamó antes esquema "causa efecto". Podemos suponer un "esquema plantilla" que en relación con un plano de un asesinato tenga el efecto de "añadir información"27 que permita una "clasificación adecuada" ${ }^{28}$ del asesinato como, por ejemplo, una venganza o un asesinato por encargo. Mencionamos este tipo de "esquema plantilla", el

\footnotetext{
${ }^{22}$ Obviamente estamos dejando de lado cualquier acompañamiento textual o verbal de lo que se ve en los planos, como podría ser el texto "1929" que nos podría indicar de una manera muy directa la "era de la gran depresión".

${ }^{23}$ Op. Cit. BORDWELL, David. Narrative in the Fiction Film. P. 34.

${ }^{24}$ Ibidem.

${ }^{25}$ Ibidem.

${ }^{26}$ Ibidem.

${ }^{27}$ Ibidem.

${ }^{28}$ Ibidem.
} 
de la causalidad, porque liga lo que se ve en un plano con lo que se ve en otro u otros de manera puramente conceptual: un asesinato se ve, pero la venganza, por ejemplo, no, esta se entiende y, a saber, de la exposición del observador a varios planos, no solamente el del asesinato.

Tanto los esquemas prototipo derivados - "(eso) es la época de la gran depresión" - como los "esquemas plantilla" causales - "el (ese) asesinato es una venganza" - no tienen una relación directa con lo que se ve, no remiten a algo que se vea, que se describa al aparecer en un solo plano, lo que nos permite el contraste con los esquemas prototipo básicos, los cuales, según vimos, remiten a lo que sí se ve, lo que se puede describir viendo un solo plano. Lo que se ve, se reconoce, en un plano - no lo que se infiere de alguna manera sin que se vea -, equivale o puede ser expresado como una proposición descriptiva. ${ }^{29}$ Esta proposición es la forma conceptual de una información sensorial, de la "información visual" a la que se refiere Bordwell. En otras palabras, los planos cinematográficos en tanto entidades fenoménicas, en este caso, entidades experimentables visualmente, portan una información sensorial que se recodifica (Dretske) conceptualmente mediante una proposición que corresponde a los esquemas prototipo de Bordwell que nosotros hemos llamado básicos. ${ }^{30}$

Solamente los esquemas prototipo básicos, más exactamente, las proposiciones descriptivas correspondientes, son portadores de información originalmente visual, sensorial. ${ }^{31}$ Estos son la materia prima de lo que Bordwell llama el "estilo". Otros esquemas como los esquemas prototipo que hemos llamado derivados, o los plantilla como los causales, no corresponden a ningún plano singular sino a combinaciones de planos, por lo tanto las proposiciones que los expresan no son descripciones de lo que se ve en ningún plano sino proposiciones inferenciales - muy básicas, más básicas que las

\footnotetext{
${ }^{29}$ Para evitar malos entendidos, señalemos que "lo que se ve" y se clasifica, cae bajo el predicado "es un X", $\mathrm{X}=$ par de amantes, robo bancario, etc., supone una experiencia un conocimiento previo, pero uno de algo que se reconoce inmediatamente, no de algo que tenga que ser inferido; así un plano mostrando gente miserable no muestra la gran depresión ya que esta simplemente no se puede mostrar, como si se puede mostrar gente pobre.

${ }^{30}$ Sobre la información codificada sensorialmente y la codificada conceptualmente, véase el capítulo 6 en DRETSKE, Fred. Knowledge and the Flow of Information. Cambridge, The MIT Press, 1982.

${ }^{31}$ Véase el capítulo 6 en Op. Cit. DRETSKE, Fred. Knowledge and the Flow of Information.
} 
que realmente le interesan a Bordwell para "construir una historia" 32 -. Las proposiciones correspondientes a tales esquemas, prototipo derivados y plantilla, no remiten, en sentido estricto, a los "materiales dados fenoménicamente" (FF 50), aunque se basen en ellos. Los esquemas prototipo derivados corresponde a una proposición que clasifica situaciones, que ya fueron vistas y pensadas, ${ }^{33}$ mientras que los esquemas plantilla de tipo causal corresponden a proposiciones lógicas, inferenciales. $^{34}$

El examen de los "esquemas" y de las proposiciones que les corresponden podría ser llevado más allá, pero lo que nos interesa aquí es simplemente poner al lado del concepto de "información" de Bordwell el concepto de proposición, ya sea meramente descriptiva del contenido de un plano o que expresa relaciones entre planos. Ambos tipos de proposiciones son el ingrediente básico del syuzhet y corresponden a información dada sensorialmente o bien a información conceptual obtenida de la combinación de planos que va ofreciendo la película. Ambos tipos de proposiciones son la expresión de las relaciones entre el "estilo" y la "trama", aquel como material fenoménico y esta como entidad conceptual. ${ }^{35}$ Por supuesto, todavía queda abierto hasta aquí el asunto de la relaciones entre la "trama" o syuzhet y la fábula o historia, pero estas relaciones son de segunda importancia para nosotros en este trabajo. Baste recordar que tanto el syuzhet

\footnotetext{
${ }^{32}$ Bordwell se refiere en su texto a muchos tipos de inferencias que se hacen a partir de la información sensorial dada por el "estilo", pero las que realmente le importan son las propias del "relato detectivesco" (Op. Cit. BORDWELL, David. Narrative in the Fiction Film. P. 38), es decir la que remiten a alguno o varios de los aspectos quién, cómo, cuándo, dónde, por qué, de una acción dada. Se trata de un nivel de inferencias muy elevado en términos cognitivos y que son puramente conceptuales, es decir, efectivamente transmediáticas, o sea, que pueden atañer tanto a la literatura como al cine por igual, dado que se basan solamente en proposiciones, sin importar si estás son parte de un zyushet literario o de uno fílmico.

${ }^{33}$ El ver epistémico, al que nos referimos en una nota de pie de página anterior. Por ejemplo, se ve un plano con americanos pobres, en otro plano se ve una fábrica cerrada, en uno más se una escena de desesperación en la bosa, todo esto se ve y se piensa. Después se clasifica englobándolo bajo el pensamiento que no corresponde a ningún plano singular de "la gran depresión", que es algo que no se ve, que solo se puede pensar; este pensamiento corresponde a un esquema prototipo derivado.

${ }^{34}$ Por ejemplo, en un plano un tipo aparece muerto, en un plano posterior vemos que tipo muerto balacea a una familia y el padre queda vivo. Entonces inferimos a) que los eventos ocurrieron en el orden inverso y que b) posiblemente el padre se vengó matando al asesino de su familia. Nótese de pasada que recomponer el orden temporal del syuzhet para "construir una historia" logrando un sentido, una sucesión comprensible de eventos, supone una inferencia respecto del orden de los eventos vistos en una secuencia de planos. Nótese que una vez que se tiene las proposiciones que describen los dos planos, se puede hacer la inferencia sobre la venganza, y para este efecto, realmente no importa que las proposiciones - la "información narrativa" de Bordwell - sean descripciones de planos u oraciones leídas en una novela.

${ }^{35}$ Un conjunto de proposiciones que se pueden relacionar lógicamente entre sí, como en el caso señalado de la venganza del padre en la nota anterior.
} 
como la fábula son entidades conceptuales, no sensoriales, y que si es que hay una dimensión mimética en el cine esta remite a lo sensorial o, para ser más exacto, a la dimensión figurativa de los planos, constitutivos del "estilo", remite a lo que se puede decir de ellos utilizando proposiciones descriptivas. De hecho postulamos de una vez que la relación entre los planos y los esquemas prototipo básicos, o las proposiciones que los expresan, es la dimensión mimética en el cine, a lo cual añadimos que la insistencia de Bordwell en un concepto de información sin mayor definición lleva a que se pierda la especificidad de los esquemas prototipo básicos como proposiciones que describen lo que se ve, es decir, que se pierda la relación entre los planos, las imágenes fílmicas, justamente, y lo que se describe de ellas, lo que se reconoce en ellas, relación que corresponde al plano como mímesis fílmica.

\section{Los planos miméticos y los planos narrativos}

En la sección anterior separamos lo que se ve en un solo plano de aquello que se puede pensar como relación entre varios planos. Justamente la atención al plano singular es minimizada por Bordwell. Su idea es que “(...) el desarrollo temporal del plano [tiene] su propia teleología (...)", ${ }^{36}$ a saber, una "teleología" narrativa. En principio, según Bordwell, la "puesta en escena", 37 es decir, todos los elementos del plano, “(...) figuras, iluminación, el set y los ropajes (...) funcionan narrativamente (...)", ${ }^{38}$ o sea, con vistas a otros planos, están "dirigidos al espectador" ${ }^{39}$ sin tener un sentido en sí mismos sino para que el espectador los relacione con otros planos. Podemos formalizar esta idea a partir de la distinción entre lo que llamaremos un plano absoluto, es decir, no relativo, un plano que antes que tener un sentido narrativo, es decir, un sentido en relación con otros planos, tiene un sentido en sí mismo. Lo opuesto, por supuesto, es el plano relativo, un plano que está en la película no por sí mismo sino solamente en relación con otros. El plano relativo es, justamente, aquel que tiene una teleología narrativa. ${ }^{40}$

\footnotetext{
${ }^{36}$ Ibid., 11.

${ }^{37}$ Ibidem.

38 Ibid., 12.

39 Ibid., 11.

${ }^{40}$ Más adelante veremos que hay "historias" fílmicas constituidas básicamente por planos absolutos.
} 
Una cita que Bordwell hace de K. Hamburger remite precisamente a los planos relativos o narrativos: "Mientras que una realidad concreta existe porque existe [es decir, en sí misma, de manera absoluta, no relativa a algo más], una realidad ficticia existe solamente en virtud de que es narrada." ${ }^{41}$ Hamburger tiene en mente la literatura, llevando la idea al cine, Bordwell dice que “(...) no es que la cámara escoja el mejor punto de vista desde el cual pueda capturar un evento que exista independientemente [en sí mismo] (...)" ${ }^{\prime 2}$ sino que la toma, es decir, el plano interesa relativamente a otros planos porque, como vimos, tiene una "teleología" narrativa. En otras palabras, no importa ninguna realidad en sí misma sino aquella que “(...) existe solamente en virtud de que es narrada (...)", como dice Hamburger, que es parte de una narración.

En claro que en este marco teórico no hay lugar para el plano singular - es decir, para la imagen fílmica propiamente dicha - definido por presentar una realidad, "(...) un evento que exista independientemente (...)", en sí mismo, que sería el candidato natural para ser considerado como mímesis en el cine. En este punto queda clara ya la insistencia de Bordwell no en una "(...) realidad [que] exist[a] en sí misma (...)" sino en el "observador"; es este el que tiene que relacionar planos, es decir, pensar, ir más allá de lo que efectivamente ve, lo que equivale a "construir" una relación entre los planos. De ahí el lema de Bordwell respecto del núcleo de su teoría: "La idea (...) es que el espectador piensa (...)", ${ }^{43}$ lema parcialmente dirigido contra la idea de que el espectador meramente observa, como el simple "testigo" ${ }^{44}$ propio de la "tradición mimética". ${ }^{45}$ De hecho, Bordwell resume su crítica a las "teorías miméticas" del cine diciendo que consisten en "un énfasis en la visión y la negación del pensamiento". ${ }^{46}$

\footnotetext{
41 Ibidem.

42 Ibid., 12.

43 Ibid., 33.

${ }^{44}$ Ibid., 9.

${ }^{45}$ Ibidem.

${ }^{46}$ Ibid., 15. Lo cierto es que, con todas sus bondades, que no son pocas, la teoría del cine narrativo de Bordwell tiene un claro sesgo intelectualista que ya hemos señalado en otra parte (CARRILLO CANÁN, Alberto, et. al. "Las emociones cinematográficas en Bordwell. En: Nuevo Itinerario. Revista Digital de Filosofía. Vol. 10, X, 2015; y CARRILLO CANÁN, Alberto; CALDERÓN ZACAULA, Marco A. "La especificidad mediática de la animación". En: Reflexiones Marginales, Año 5, No. 30, 2015).
} 
En realidad, en el marco teórico de Bordwell la pareja "observador" - "narración" señaliza el interés del autor por considerar no planos absolutos, no planos que interesen en sí mismos, al margen de otros planos, sino, justamente, por el contrario, el interés de la teoría por los planos relativos a otros, por los planos con una "teleología" narrativa, a los que llamaremos planos narrativos. Precisamente el interés en los planos narrativos conlleva, correlativamente, la desaparición teórica de los planos absolutos, a los cuales llamaremos planos miméticos. En otras palabras, el enfoque de Bordwell orientado a resaltar los planos narrativos lleva a que en su teoría los planos miméticos desaparezcan sin más.

\section{El plano narrativo y la edición.}

\section{Un engaño acerca de la realidad "filmada"}

Queda claro que a Bordwell le interesan las relaciones entre planos, aquello que no se ve pero se "piensa" con base en ellos, mientras que los planos en sí mismos pierden para él toda importancia - en todo caso son, como veremos más adelante, un fenómeno meramente "local", mientras que el está interesado en el problema global de la "construcción de una historia" -. Justamente las secuencias en tanto encadenamientos de planos no corresponden a lo que podría ver un observador porque en general simplemente no hay un punto de vista que pudiera corresponder coherentemente a tal observador, así sea este un "observador ideal". ${ }^{47}$ Es decir, los planos constitutivos de las secuencias, en general, no conllevan un punto de vista desde donde sus contenidos pudieran ser observados coherentemente. Correlativamente eso significa que no hay nada que pueda ser observado y sea el correlato real de la secuencia respectiva. A diferencia de un plano, en el caso de una secuencia, en general, lo que sus planos muestran no es nada que efectivamente pase delante de la cámara - "una realidad independiente" -, así sea para ser observado en partes. Bordwell insiste en que la cadena de sucesos que supuestamente ocurrirían no existe; es el observador quien une los planos en una

\footnotetext{
${ }^{47}$ Op. Cit. BORDWELL, David. Narrative in the Fiction Film. P 10.
} 
"construcción imaginaria". ${ }^{48}$ En otras palabras, la "historia" de una película es una entidad meramente conceptual, imaginaria, no fenoménica, nada que hubiera podido ser experimentado, a pesar de que para su "construcción" la base sea la dimensión sensorial de la película, lo que hemos visto que Bordwell llama el "estilo". A fin de cuentas se trata de que ni una secuencia ni una película conllevan ninguna "realidad profílmica" que pudiera ser registrada, mostrada y observada. Lo que realmente ocurre es que "(...) el espectador construye la historia a partir de estímulos (...)". ${ }^{49}$

Claramente lo que está aquí en juego es la edición o montaje. ${ }^{50}$ Un ejemplo muy sencillo sería la secuencia constituida por el plano de un personaje que, filmado desde una altura de varios metros, se lanza desde un puente a un río muchos metros más abajo, seguido por un plano del personaje que cae al agua y emerge de ella filmado un metro por debajo de la superficie del agua. Dado lo peligroso del supuesto salto, lo que se hará será dejar caer un muñeco con los brazos extendidos y un peso en la cabeza para que se incline cabeza abajo ya en los primeros momentos de la caída. Cuando esto pasa se deja de filmar y no se muestra el desarrollo de la caída hasta su final. Por supuesto que aquí hay un engaño, se trata de que el espectador crea que el personaje efectivamente realiza el peligroso salto cuando en realidad lo que cae, pareciendo ser alguien que salta, es un muñeco. ${ }^{51}$ El siguiente plano con el actor que es el personaje entrando al agua y nadando para volver a la superficie se realiza con total independencia temporal del primero. Es claro que en realidad no se ve ningún salto del puente hasta el agua, eso, que sería el "evento" relevante para la "historia" de la película, no existe, simplemente no sucede - y

\footnotetext{
${ }^{48}$ Ibid., 49.

${ }^{49}$ Ibid. 15. Hacia el final de este texto veremos que Bazin tiene una teoría realista del cine que sostiene prácticamente lo contrario. Se trataría, para Bazin, más que de construir una historia, de verla. No resulta extraño que Bordwell ubique a Bazin como uno de los teóricos del cine como mímesis (Cfr. Ibid., 9-10).

${ }^{50}$ En realidad el término "edición" es técnico, se refiere un procedimiento, mientras que el término "montaje" es un término de teoría estética, consolidado en los esfuerzos por definir la naturaleza de la imagen fílmica y remite ya a Malreaux. Bazin nos dice que "[r]especto del montaje, proveniente inicialmente, como todos sabemos, de las obras maestras de Griffith, tenemos la tesis de Malreaux en su Psicología del cine de que fue el montaje lo que dio nacimiento al cine como arte, separándolo de la simple fotografía animada, en resumidas cuentas, creando un lenguaje." (BAZIN, André. What is Cinema? Vol. 1. California, University of California Press, 2005, p. 24) En otras palabras, el término "montaje" remite a una discusión estética, no tiene nada que ver con la edición en tanto técnica.

${ }^{51}$ En nuestra teoría hemos llamado a estos engaños, no ilusión, sin más, como suelen hacerlo los teóricos cinematográficos, sino ilusión epistémica. Volveremos a esto más adelante.
} 
por eso no queda registrado por la cámara en un solo plano continuo -. Generalmente la secuencia de los dos planos lleva a que, inconscientemente, el espectador caiga en un segundo engaño, el de creer que el personaje cayó al agua como resultado del peligroso salto. Los dos engaños combinados constituyen el engaño de creer que se realizó un salto en tanto evento completo que en realidad no se ve por el hecho de que no se registró porque simplemente no ocurrió.

En el caso discutido, tendríamos un ejemplo claro de que la secuencia de los dos planos no solo no corresponde a ningún punto de vista coherente que pudiera tener un testigo del evento, sino de que el hecho de que no haya tal punto de vista coherente al evento se corresponde con el hecho correlativo de que el supuesto evento ni siquiera ocurre. El evento del salto al agua no es ninguna "realidad profílmica" que pueda ser registrada por la cámara, se puede decir, utilizando a Hamburger, el evento es “(...) una realidad ficticia [que] existe solamente en virtud de que es narrada (...)", en este caso, de que a causa de la edición, el observador pensante, en el que insiste Bordwell, crea que se trata de una realidad existió delante de la cámara - o las cámaras -.

El ejemplo considerado remite no a una cadena de eventos diferentes sino a las partes de un evento, y ya en este caso, de un solo "evento", tenemos el ejemplo de una relación temporal entre planos que es su orden en la edición, que lleva a que el observador "piense" - como dice Bordwell - en el sentido de creer que hay un evento, de construir mentalmente el evento del salto al agua. Bordwell diría que el evento es una "construcción imaginaria". En la siguiente sección examinaremos la noción de imaginación así aplicada, el cual, en sentido estricto no quiere decir realmente imaginación sino ficción, una realidad ficticia, pero por lo pronto debemos sacar consecuencias para el concepto de mímesis.

La secuencia de los dos planos es la secuencia de dos mímesis, la primera, la de alguien que inicia un salto desde un puente al agua muchos metros debajo de dicho puente, la segunda, la de alguien que como resultado de un salto entra al agua y nada de 
regreso a la superficie. ${ }^{52}$ Estos dos eventos sí pueden ser aislados y son cada uno una realidad filmada, sin importar que haya trucos o no. Sin embargo, para la "historia" de la película no tienen sentido como eventos aislados sino únicamente como partes de un solo evento que no existe, independientemente de que el espectador crea o no crea en la realidad del evento. El evento total del "salto del puente hasta el agua y el regreso del personaje a la superficie de la misma", es lo que tiene sentido para la "historia" de la película, y tal evento inexistente es una construcción mental del espectador provocada por la secuencia, causada por ella. Queda claro entonces que el evento es solamente mental, que no existió como algo $E$ que hubiera podido ser - grabado y luego - mostrado al espectador de manera que ese algo $E$ pudiera ser considerado de alguna manera mímesis de otra cosa. El evento del salto completo, en tanto magnitud o entidad narrativa, es solamente mental, no hay ninguna mímesis de él.

\section{El plano narrativo y la edición.}

\section{La ficción y la mimesis}

Supongamos ahora un salto de un puente al agua de un río desde una altura relativamente pequeña que sí se realiza y que es registrado por una cámara cinematográfica - o varias - ya sea de frente, desde arriba o desde algún otro ángulo. En este caso el evento sí tiene existencia, es una "realidad profílmica", y como antes es el evento que tiene sentido para la historia de la película. Se registra cómo el personaje, no un muñeco ni un doble, salta el agua y cómo entra a la misma y regresa a la superficie, aunque en este caso no haya ninguna toma bajo el agua.

En este caso el salto, el evento registrado existe, pero no existe independientemente de la cámara, no es algo que ocurriera al margen de si iba a ser grabado o no, sino que ocurrió para ser grabado, es decir, el salto es una realidad escenificada para la cámara, una realidad relativa a la cámara, a pesar de que sea realidad y en tanto tal pueda ser registrada. El evento "profílmico" existe para la cámara, para el filme, por lo tanto no es una realidad absoluta, una realidad en sí misma, una realidad al

\footnotetext{
${ }^{52}$ En realidad, la noción de mímesis aquí utilizada requiere una importante precisión que haremos más abajo.
} 
margen de toda cámara que pudiera o no grabarla. Recordando otra vez a Hamburger podemos decir nuevamente que el evento es “(...) una realidad ficticia [que] existe solamente en virtud de que es narrada", pero el sentido de la frase es muy diferente. En este caso el salto no es una mera construcción mental, en este caso el salto sí existe aunque solamente en virtud de que va a ser filmado, registrado por una cámara. ${ }^{53}$

En el ejemplo del salto en el que se cree como producto de la secuencia de dos planos, la "realidad ficticia", el salto completo, que es un evento de la "historia" de la película, es una realidad puramente mental, no hay ningún correlato de él en la realidad, así fuera este una "realidad profilmica", es decir, solamente para ser filmada. Sin embargo en el caso del salto que sí se filma, sí existe la "realidad profílmica", no es ninguna realidad puramente mental, aunque sí es una "realidad ficticia", existente solamente para ser filmada. Queda claro que "profílmico" equivale a decir relativo a la cámara, que ocurre por mor de la cámara y, por ello, ficticio. El sentido de "ficción" tiene en ambos casos un significado muy diferente. En el primero la ficción es algo solamente mental, no registrable porque simplemente no existe. En el segundo caso el evento sí existe, y de hecho se registra, pero es ficción porque es escenificado para ser filmado, es la pura mímesis en el conocido sentido con el que la tradición aristotélica asocia al término con una acción fingida en el teatro, ${ }^{54}$ una acción que en tanto tal excluye el que solamente se le piense porque realmente se ve, aunque sea fingida, escenificación. Hasta aquí queda claro que cuando Bordwell se refiere a una construcción imaginaria se trata de una ficción puramente mental, algo que no existe profílmicamente.

El propio Bordwell señala de pasada que para Eisenstein "[I]a edición transforma a la mise-en-scène teatral en planos $(. . .)^{255} \mathrm{y}$, justamente, del "evento profílmico" ${ }^{56} \mathrm{De}$ hecho, el tipo de planos recién discutidos, es decir, los que muestran el evento, son lo que

\footnotetext{
${ }^{53}$ Al final de este trabajo volveremos sobre esto en la comparación con eventos que tienen tanta importancia en sí mismos que se realizan enfrente de la cámara, es decir, para ser filmados, pero no son ninguna ficción.

${ }^{54}$ Véase en Bordwell: "La concepción aristotélica de mímesis se aplica primeramente a la actuación teatral." (Op. Cit. BORDWELL, David. Narrative in the Fiction Film. P. 4)

55 Ibid., 14.

56 Ibid., 15.
} 
Bordwell llama "técnicas fílmicas (...) involucrando el 'evento profílmico" ${ }^{57}$ y simultáneamente señala que "incluso" ellas "(...) funcionan narrativamente (...)", 58 así puedan ser concebidas como una "trasformación" de la puesta en escena teatral en plano fílmico, lo que remite a su afirmación de que "[n]ecesitamos una teoría de la narración [cinematográfica] que [a] no esté ligada a vagas analogías atómicas entre sistemas de representación, y que [b] no privilegie ciertas técnicas $(. . .)^{\prime \prime} .{ }^{59}$ Todo parece indicar que nuestra afirmación de que el plano que muestra el "evento profílmico" ${ }^{60}$ no es otra cosa que la mímesis cinematográfica caería bajo la crítica de Bordwell a las "vagas analogías atómicas entre sistemas de representación", en este caso entre el teatral y el fílmico. En general Bordwell rechaza lo que él vería cómo meras "analogías locales" ${ }^{11}$ entre el cine y otros medios y explícitamente rechaza “(...) analogías superficiales entre el cine y otros medios - la literatura, el teatro (la aproximación mimética) (...)" ${ }^{\prime 2}$ Este es un buen momento para precisar el concepto de mímesis utilizando el ejemplo del plano que realmente muestra el salto del personaje del puente al agua.

Ciertamente la acción se realiza, pero, independientemente de su lugar en la "historia" fílmica de que se trate, lo importante es que se trata de un "evento profílmico", es decir, dependiente de la cámara, ficticio no porque no se realice sino fingido porque no se realiza con independencia de la cámara; es un fingimiento, una actuación, o ficción y no "una realidad que exista en sí misma", como podría decir Hamburger. Nótese que si bien el plano del salto tiene una "teleología" narrativa, está para ser ligado con otros, para que, pensando, el observador lo relacione con otros, de todos modos, el salto es un fingimiento, una ficción en sí mismo, y por tanto mímesis, a pesar de que también, adicionalmente, sea una ficción narrativa, es decir, con vistas a la historia de la película, una ficción relativa. El plano mismo del salto es el registro de una actuación, el registro de una mímesis y, en

\footnotetext{
57 Ibid., 12.

58 Ibidem.

${ }^{59}$ Ibid. 26. Más abajo examinaremos el sentido de la demanda [b], de que la teoría “(...) no privilegie ciertas técnicas (...)" (Ibidem). Aquí podemos adelantar un objetivo de tal crítica es la teoría de Bazin, con las dos leyes estéticas que discutiremos ampliamente abajo, las cuales remiten al plano abierto y al plano continuo.

60 Ibid., 12.

61 Ibid., 25.

62 Ibid., 49.
} 
tanto tal registro, podemos decir que es mimético en sentido derivado. Si bien ciertamente, en sentido estricto, el plano no es mímesis, sino solamente el registro de una mímesis, a fin de cuentas, lo que el espectador ve conscientemente no es el plano, su conciencia no es primariamente la del plano como registro sino de la mímesis que este registra, la realidad profílmica. Por ello diremos que la mímesis en sentido básico, estricto, es la actuación registrada, mientras que el plano, en tanto registro de esa mímesis primaria, es derivada, secundariamente, mimético.

Llegamos a la conclusión de que el plano que muestra el salto completo, en tanto inserto en alguna secuencia de una película, tiene una doble naturaleza. Por un lado el plano que muestra el evento completo es una mímesis en sentido secundario o derivado , ya que es el registro de un fingimiento, de una mímesis en sentido primario. Por otro lado, el mismo plano, con todas y sus mismas características fenoménicas independientemente de en qué ponga atención el espectador - tiene una teleología narrativa, tiene un sentido adicional al de aquello que muestra y que le surge únicamente en su relación con otros planos, ya sean estos anteriores o posteriores en la secuencia. Podemos decir que el plano del evento completo tiene una doble naturaleza, la de plano absoluto y la de plano relativo, la de plano mimético - que no tienen los planos fraccionarios del primer ejemplo - y la de plano narrativo. El plano del evento completo es, pues, una doble ficción, una ficción sensorial, de una realidad relativa a la cámara y, además, una ficción conceptual, de una realidad con sentidos relativos a otros planos, relativa a relaciones con ellos que únicamente se piensan pero que no corresponden a nada sensorial y que, por lo tanto, son transmiméticas - y que son las únicas que en realidad le importan a Bordwell -. La dimensión estrictamente narrativa, la que atañe a relaciones con otros planos y, por tanto no sensorial sino conceptual, es, esa sí, transmimética. Bordwell excluye de su teoría esta ambigüedad del plano cinematográfico y, a pesar de que considere con amplitud el "estilo" o dimensión sensorial del cine, en realidad él se queda con la dimensión transmimética del plano. 
Ya vimos que Bordwell insiste en que el "evento profílmico" - cuando existe, que, según lo aclaramos en nuestro segundo ejemplo, con mucha frecuencia no es el caso ${ }^{63}$ es ya una escenificación narrativa, el señalamiento de Bordwell en que las luces, el ropaje, etc., tienen una teleología narrativa, y esto no en el sentido inmediato de que el fingimiento de un evento sea relativo a toda una cadena de eventos, sino en el sentido más profundo, específico para el caso fílmico - aunque el propio Bordwell no lo haga explícito - de que las relaciones entre eventos de la "historia", a diferencia del caso del teatro, en el cine no serán mostradas, puestas a la vista del espectador, ${ }^{64}$ sino más profundo de que dichas relaciones tendrán que ser pensadas - Bordwell: inferidas -. Sin embargo, ya sea que el evento tenga relaciones con otros eventos mostradas o meramente inferidas, tales relaciones no afectan al concepto de mímesis como fingimiento o actuación. Una cadena de fingimientos es eso, una cadena de fingimientos, independientemente de las relaciones que dichos fingimientos tengan entre ellos. Por supuesto, a Bordwell siempre le interesa más el problema "global" o "total" que el "local", es decir, la "historia" que el "evento", pero ya sea que los eventos resulten en una historia o no, cada evento - si es que ocurre como evento completo - es una mímesis. Tan el evento aislado califica para mímesis que en el caso de la pintura se tiene la idea tradicional de mímesis como copia o reproducción de la naturaleza y, así, la pintura de un caballo en el campo o una pintura de un paisaje, son miméticas a pesar de carecer de toda relación con algún evento o situación adicional a la que se muestra en la pintura misma.

\section{El plano narrativo y la edición.}

\section{Imaginación, ilusión y mimesis}

En esta sección reuniremos a) el resultado de substituir el término vago de Bordwell de "información" por el de "proposición" con b) el resultado de considerar al

\footnotetext{
${ }^{63}$ Véase abajo la noción de Bazin del "análisis" - fraccionamiento de la realidad - como opuesta a la "continuidad de la realidad".

${ }^{64}$ De hecho una forma de negar que el cine sea una mimesis es también la de insistir en que el cine no es espectáculo, así ya al iniciar su obra Bordwell nos dice que "[l]as teorías miméticas conciben la narración como la presentación de un espectáculo: un mostrar." (Ibid., 3) Más adelante, por ejemplo, Bordwell critica a teóricos cinematográficos como Münsterberg y Arnheim porque, nos dice, "(...) ninguno trata de definir el cien fuera del dominio del espectáculo." (Ibid., 9)
} 
plano que muestra un evento completo como mímesis, así sea mímesis en sentido secundario o derivado. De la combinación de estos resultados obtendremos un concepto positivo de ilusión, no como error, que es la posición dominante en la tradición estética y en particular cinematográfica, ${ }^{65}$ adicionalmente precisaremos un concepto de imaginación que nos servirá para dar otro aspecto a la teoría de Bordwell, leída no en los términos que a él le interesan, los de la "construcción de una historia" a partir de "inferencias", sino de relaciones entre ilusión e imaginación. Para llegar a todo ello empezaremos por reconsiderar brevemente la teoría de Bazin acerca de la ilusión y su relación con el plano que muestra un evento completo, así como con su teoría de lo que hemos llamado el plano absoluto. Podemos partir de un ejemplo muy claro de la crítica de Bazin al montaje o edición, en favor del evento que muestra el evento completo.

Bazin nos dice que le parece que se podría “(...) establecer el siguiente principio como un ley de la estética [cinematográfica]. 'Cuando la esencia de una escena demanda la presencia simultánea de dos o más factores en la acción, el montaje debe ser excluido."”66 En general lo que preocupa a Bazin es que la edición “(...) interrumpe el flujo (...) espacial de la acción (...)" ${ }^{67}$ Bazin argumenta su "ley de la estética" mediante un examen de una secuencia de la película inglesa Where no Vultures Fly (1951):

La secuencia que tengo en mente inicia de la manera más convencional. Sin que sus padres lo sepan el niño se alejó del campamento y encontró un cachorro de león al que su madre había abandonado temporalmente. Sin conciencia del peligro el niño toma al cachorro y se lo lleva. Mientras tanto la leona (...) regresa a su cubil y empieza a seguir el camino del niño (...). La leona sigue al niño de cerca. El pequeño grupo es ya visible desde el campamento, momento en que los distraídos padres ven al niño y a la leona, que claramente está a punto de saltar sobre el raptor imprudente en cualquier momento. ${ }^{68}$

\footnotetext{
${ }^{65}$ Sobre la contraposición entre el concepto negativo de ilusión y el de ilusión estética como concepto teórico para las artes figurativas, incluido el cine, ver: CARRILLO CANÁN, Alberto; RIVAS LÓPEZ, Víctor G. "Ilusión, emoción y sentimiento en el cine". En: Reflexiones Marginales, Año 6, No. 32, 2016.

${ }^{66}$ Op. Cit. BAZIN, André. What is Cinema? Vol. 1. P. 50.

${ }^{67}$ Ibid., 49. Ver más abajo el concepto de edición como "análisis", fraccionamiento de la realidad.

68 Ibidem. Nota de pie.
} 
En este punto empieza el análisis de Bazin:

Hasta este punto todo se mostró en montaje paralelo y el un tanto inocente intento de suspenso aparece como bastante convencional. Entonces, de pronto, para nuestro espanto, el director abandona su montaje de planos separados que ha mantenido aislados los personajes, y en vez de eso nos ofrece a los padres, el niño y a la leona, todos en un mismo plano abierto. Este encuadre, en el que no hay lugar para ningún truco, da autenticidad retroactiva a todo el montaje bastante banal que lo precedió. A partir de este momento, y siempre en el mismo plano abierto, vemos al padre ordenarle a su hijo que se detenga - la leona se ha detenido pocas yardas atrás - y que hecho esto ponga la cachorro en el suelo y que camine hacia delante sin apresurarse. Después de esto la leona avanza calmamente, toma al cachorro y regresa a la maleza mientras los padres locos de alegría corren hacia el niño. ${ }^{69}$

Terminada la descripción de la secuencia, Bazin continúa con su análisis, diciéndonos que

[e[s evidente que considerada desde el punto de vista del recuento, esta secuencia hubiera tenido el mismo significado simple si se hubiera filmado enteramente en montaje o sobreponiendo planos en uno, pero en ninguno de dichos casos el evento se habría desarrollado frente a la cámara en su realidad física y espacial. ${ }^{70}$

En otras palabras, utilizando meramente edición en vez del plano abierto continuo el encuentro entre los personajes y los animales no se habría escenificado, no habría tenido "su realidad física y espacial" y, por lo tanto no podría haber sido registrado por la cámara. ${ }^{71}$ Entonces la secuencia, “(...) habría tenido solamente el impacto de un historia y no de un evento real (...)", es decir de algo meramente pensado a partir de un relato o

\footnotetext{
${ }^{69}$ Ibidem. Nota de pie.

70 Ibidem. Nota de pie.

${ }^{71}$ Al final de este texto regresaremos al asunto del plano abierto y continuo.
} 
historia y no de algo visto a partir de un registro de naturaleza fotográfica. En los términos de lo arriba discutido, la cercanía entre la leona y los humanos hubiera sido una relación sugerida por los planos, "pensada" o "construida" por un observador que no la vio. ${ }^{72}$ Recordemos aquí que, como el propio Bordwell lo señaló, justamente el ver no le interesa tanto como el pensar y que Bordwell considera que la deficiencia de lo que él llama las "posición mimética" reside en "un énfasis en la visión y la negación del pensamiento". ${ }^{73}$

Por su parte, Bazin continua diciendo que

(...) no habría habido ninguna diferencia entre la escena como plano y un capítulo en una novela en el que se hubiera relatado el mismo episodio imaginario. Por lo tanto los valores morales y dramáticos del episodio hubieran quedado en un nivel muy mediocre. Por el contrario, el encuadre final que implicó colocar a todos los personajes en una situación real [existente, así sea para la cámara, una escenificación] nos lleva de un solo golpe a las cumbres de la emoción cinematográfica. ${ }^{74}$

Por supuesto, la "emoción cinematográfica", tal como la entiende aquí Bazin está relacionada con el espectáculo, con lo que se ve, y Bordwell, consecuente con su tendencia a minusvalorar la dimensión visual en favor de la cognitiva - "pensante" -, propia de la "construcción de una historia", minusvalora igualmente la dimensión espectacular del cine. Esto último corresponde a la perfección a la repetida tesis de Bordwell de que el espectáculo mimético, lo que según él, el cine no es, está calculado para el ojo de un observador. ${ }^{75}$ Queda claro, entonces, que la dimensión emotiva subrayada por Bazin en el pasaje citado - relativa al espectáculo, a la mímesis y su

\footnotetext{
${ }^{72}$ Este es uno de los casos de lo que Bordwell llama "construcción imaginaria".

${ }^{73}$ Op. Cit. BORDWELL, David. Narrative in the Fiction Film. P. 15.

${ }^{74}$ Op. Cit. BAZIN, André. What is Cinema? Vol. 1. P. 49. Nota de pie.

${ }^{75}$ Véase por ejemplo: “(...) la Grecia de Aristóteles tuvo en ambos, el teatro y la pintura, una conciencia tácita de cómo calcular el espectáculo en relación con la vista del espectador." (Op. Cit. BORDWELL, David. Narrative in the Fiction Film. P. 4)
} 
correlato subjetivo, la ilusión, es algo que está fuera del foco de atención de Bordwell. Pero regresemos al análisis de Bazin, quien inmediatamente nos dice que

[n]aturalmente, tal logro fue posibilitado por el hecho de que la leona era semidomesticada y antes de la filmación había estado viviendo en estrecho contacto con la familia. Esto no es lo importante. Lo importante no es si el niño realmente corrió el riesgo que pareció correr sino que el episodio fue filmado con el debido respeto por su unidad espacial. El realismo reside aquí en la homogeneidad del espacio. $^{76}$

Homogeneidad que está ausente o incluso puede ser destruida por la edición. Consecuentemente, Bazin continua diciendo que “(...) entonces vemos que hay casos en los que el montaje, lejos de ser la esencia del cine es, en realidad, su negación. La misma escena, entonces, puede ser literatura pobre o gran cine, según que se utilice el montaje o un plano abierto." 77

El último pasaje no tiene desperdicio. La primera idea, la de que el montaje pueda ser la negación del cine en vez de su esencia es una tesis verdaderamente radical que choca de frente con el supuesto de Bordwell respecto de la edición no solamente como lo más natural en el cine, sino justamente como aquello que a fin de cuentas es el procedimiento fílmico que Bordwell ve como la base o la causa para la "construcción de una historia" por parte del observador. ${ }^{78}$ La segunda parte del fragmento es de gran

\footnotetext{
${ }^{76}$ Op. Cit. BAZIN, André. What is Cinema? Vol. 1. P. 49. Nota de pie.

77 Ibid. 50. Nota de pie. Véase atrás la nota de pie de página en la que citamos a Bazin quien se refiere a la tesis de Malraux de que el "cine como arte", y no como simple "fotografía animada", empieza con el montaje.

${ }^{78}$ Por supuesto, se trata de una tesis muy radical de Bazin que no solamente choca con las ideas de Bordwell sino de la mayor parte de la teoría cinematográfica, por ejemplo, recuérdese que no solamente para Malraux sino también para la narratología en su conjunto el cine necesariamente se basa en el montaje o edición ya que la edición es la que genera las combinaciones - "sintagmas" - cuyo estudio es el centro de la teoría narratológica del cine, según lo explica Metz (Op. Cit. METZ, Christian. Film Language. A Semiotics of Cinema. Chicago. P. 36). En cuanto a Bordwell, hay que señalarlo aquí de una vez en su esencia porque no nos ocuparemos de ello en este texto, es la edición conjuntamente con el "barajar" el orden temporal de los eventos, lo que en el proceso de presentación de la película genera "huecos [gaps]" informativos, que obligan al espectador hacer inferencias. Sobre esto ver nuestro texto Op. Cit. CARRILLO CANÁN, Alberto, et.
} 
alcance teórico puesto que da la pauta para lo que con ser evidente tiende a ser desconocido, en particular por Bordwell con su énfasis en el observador que más que ver piensa: lo literario en general y en particular en el cine es aquello que no se ve sino sobre lo cual solamente se piensa, mientras que lo auténticamente cinematográfico, lo que remite al cine como medio con base fotográfica, es lo que se ve, lo registrado. Así, el simple pensar en la proximidad de los personajes que son la leona y su cachorro y el niño y su familia, es algo meramente literario porque no se ve, porque la edición en este caso substituye la situación - así sea escenificada - por el solo sugerirla para que sea meramente imaginada, mientras que, por el otro lado, el plano abierta mostrando - el espectáculo, tan minusvalorado por Bordwell - juntos a todos los personajes en un registro fotográfico, es cine y, a saber, conlleva la ilusión generada por la escenificación o fingimiento de una leona salvaje y su cachorro en la proximidad de un grupo de personas atemorizadas. La escena filmada es la mímesis o el registro de ella, que provoca la ilusión de una situación que en realidad no se da porque la leona no es salvaje, más aún, conoce a los humanos por haber convivido largamente con ellos. Conviene señalar muy brevemente aquí el concepto positivo de ilusión, totalmente diferente de la noción común de la ilusión como engaño.

En el ejemplo de Bazin del plano abierto mostrando simultáneamente a la leona con los humanos, la ilusión en tanto ilusión estética - que es la que le interesa a Bazin - es el estado mental consistente en "aceptar que la leona está a punto de saltar sobre el niño sin creer que sea el caso que la leona está punto de saltar sobre el niño", no se cree que sea el caso que la leona está a punto de saltar sobre el niño porque el espectador sabe

al. "Las emociones cinematográficas en Bordwell." Bordwell también habla del "agujero [hole] informativo en la fábula" (Op. Cit. BORDWELL, David. Narrative in the Fiction Film. P. 55) Tales "huecos" o "agujeros" surgen por ciertas "correspondencias entre la fábula y el syuzhet" (Ibid., 54), se trata de correspondencias en las que hay "disparidades" (Ibidem), ocurre que "[t]odo syuzhet selecciona qué eventos de la fábula va a presentar y los combina de maneras particulares. La selección crea agujeros [gaps] (...)" (Ibidem). Lo importante aquí no es exactamente cómo surgen los "agujeros" sino que surgen de la edición y que son ellos los que obligan a pensar - a hacer inferencias - en vez de simplemente observar, de ver la película como un flujo continuo de eventos con su sentido inmediato en ese mismo flujo. Estamos con esto en la situación básica de la teoría de Bordwell que rechaza la idea del cine como mímesis: es la edición la que evita que los planos refieran al flujo continuo de una realidad "profilmica". 
que "solamente se trata de una película". ${ }^{79}$ Se trata de una ilusión basada en el hecho de que se ve a la leona en cierta actitud en la proximidad del niño. Si se tratara de dos planos en el que en uno de ellos se ve a la leona en actitud de saltar y en el otro se ve al niño, la relación consistente en que el salto de la leona va a ser sobre el niño no se vería, sino que sería solamente pensada, es decir, $P=$ "la leona está por saltar sobre el niño" sería un pensamiento sin base sensorial directa, ya que no se ve ninguna proximidad entre la leona y el niño. Entonces el "aceptar que $P$ sin creer que sea el caso que $P$ ", donde $P=$ "la leona está a punto de saltar sobre el niño", sería una mera imaginación. Tal caso es el de la imaginación estética que se da igualmente cuando, como lo menciona Bazin, en una novela se lee la proposición $P=$ "la leona está a punto de saltar sobre el niño", sin ver la proximidad entre la leona y el niño. A fin de gozar la ficción literaria tenemos el estado mental de "aceptar que $P$ sin creer que $P$ sea el caso". En resumen, el plano abierto produce en el espectador un ilusión estética mientras que el montaje o edición que separa a los participantes en la acción produce una imaginación estética exactamente igual a la que es propia de la literatura. Con ello queda clara la idea de Bazin, que según que se recurra al montaje o no, se está frente a gran cine o a literatura común y corriente. Los planos separados de la leona y del niño serían planos narrativos, algo totalmente diferente del plano mimético a cuyo contenido corresponde a la proposición descriptiva $P$ = "la leona está a punto de saltar sobre el niño". Es claro que en los planos narrativos mencionados ninguno corresponde a la mímesis de que "la leona está a punto de saltar sobre el niño" mimesis constituida por el plano abierto que cumple con la "ley de la estética" de Bazin relativa a la "homogeneidad del espacio".

\section{El plano mimético y la ley estética referida al tiempo}

Ciertamente nuestro ejemplo del plano mostrando el salto del puente al río es de naturaleza diferente a la "ley de la estética" cinematográfica de Bazin enunciada arriba y

\footnotetext{
${ }^{79}$ Sobre esta aceptación y en general sobre la estructura "aceptar que $P$ sin creer que sea el caso que $P$ ", como en este caso donde $P$ es la proposición "la leona está a punto de saltar sobre el niño", véase, por ejemplo, Op. Cit. CARRILLO CANÁN, Alberto; CALDERÓN ZACAULA, Marco A. "La especificidad mediática de la animación"; y Op. Cit. CARRILLO CANÁN, Alberto; RIVAS LÓPEZ, Víctor G. "Ilusión, emoción y sentimiento en el cine".
} 
que demanda la proximidad de todos los personajes de una situación en un solo plano, es decir, que prescribe la continuidad del flujo espacial de la situación en contra de la práctica usual en el cine de eludir o incluso romper la continuidad espacial que es el marco de una situación o de un evento utilizando la edición, consistente en hacer planos separadas que luego se presentan en secuencia, con lo cual el flujo espacial de una evento - más aún que el temporal - queda eliminado. Sin embargo, si bien en el ejemplo del salto mostrado en una sola toma no hay varios personajes, lo que sí hay es el registro del salto como proceso en su integridad, es decir, se tiene el flujo temporal de un evento en su integridad. En realidad el propio Bazin teoriza muy claramente la bondad del plano que muestra un evento completo. En otra parte hemos tratado ampliamente el manejo que Bazin del plano que muestra un evento en su integridad, ${ }^{80}$ por lo que aquí nos limitaremos a exponer brevemente la idea central.

Según Bazin, lo importante para el cine realista es "el manejo de los hechos por ellos mismos", ${ }^{11}$ es decir, en términos absolutos y no en términos relativos a una narrativa. ${ }^{82}$ De esta manera, el cine realista se distinguiría, en primer, lugar por la manera en la que presenta los eventos, a saber, de manera absoluta y no relativa. Así, refiriéndose a película de Visconti La Terra Trema (1948), Bazin nos dice

Visconti parece haber querido, en cierto sentido sistemático, basar la construcción de su imagen en el evento mismo. Si un pescador enrolla un cigarrillo, no nos ahorra nada: vemos la operación completa; no resulta reducida a su significado dramático o simbólico, que es lo usual en el montaje. ${ }^{83}$

\footnotetext{
${ }^{80}$ Ver nuestro amplio trabajo "Del neorrealismo fotográfico de Umberto $D$ al hiperrealismo digital de The Adventures of Tintin. Bazin y la ontología del relato cinematográfico". En: CARRILLO CANÁN, Alberto. Fotografía, cine, juegos digitales y narratividad: estudios sobre la sensibilidad novomediática. México, BUAP \& Itaca, 2013.

${ }^{81}$ Op. Cit. BAZIN, André. What is Cinema? Vol. 1. P. 159.

${ }^{82}$ Ver el ensayo señalado en la nota anterior.

${ }^{83}$ BAZIN, André. What is Cinema? Vol. 2. California, University of California Press, 2005, p. 43. Cuando Bazin menciona aquí el montaje, se refiere a la "edición clásica" (Ibid., 28) y su "análisis" (Ibidem) o fraccionamiento del "continuo de la realidad" (Ibidem). De acuerdo con Bazin, en la "edición clásica" lo que hay es "realidad separada en tomas sucesivas son solamente una serie de puntos de vista lógicos lo subjetivos respecto de un evento. Un prisionero en una celda espera la llegada del verdugo. Su mirada
} 
Obviamente la idea de "basar la construcción de la imagen en el evento mismo" conlleva la dimensión exterior, es decir la definición sensorial del evento - no su definición lógica causal o de información de algún tipo según una teleología narrativa -, de hecho, en este caso “(...) vemos la operación completa (...)". La alternativa sería reducirla "a su significado dramático o simbólico", justamente, reducirla a una teleología narrativa, por ejemplo, presentando un fragmento del evento para hacerlo corresponder a la proposición "el pescador prepara un cigarro", la cual, a si vez, tendría un carácter no meramente descriptivo sino "una teleología narrativa", es decir, sería necesaria para comprender la historia de la película, por lo que la acción que la acción descrita no sería absoluta, es decir, sin que importara en sí misma. Este papel narrativo del plano mostrando el fragmento del evento sería la reducción del evento "a su significado dramático o simbólico". De hecho tal reducción tiende a ser la regla con el montaje, porque el montaje en tanto montaje de una historia no necesita definir los planos en términos absolutos, es decir, sensorialmente, sino conceptualmente, llevando a la proposición que equivale a una porción de lo que Bordwell llama "información" dada por el syuzhet, porque de lo que se trata es de la comprensión de la historia sugerida y para esto no es necesaria aquella delimitación sensorial del evento que corresponde a su escenificación como un "evento profílmico".

Vemos, entonces que la "ley de la estética" cinematográfica de Bazin, en tanto regla fílmica que pide presentar a todos los participantes de una acción o situación en su proximidad espacial los unos a los otros usando el plano amplio, lo cual sería una "ley" relativa al espacio del evento, tiene su complemento en lo que podríamos llamar otra ley de la estética cinematográfica consistente en respetar el flujo temporal de un evento,

angustiada se clava en la puerta. En el momento en que el verdugo está a punto de entrar podemos estar seguros de que el director va a cambiar a un plano cerrado de la manilla de la puerta girando lentamente. Este close-up queda justificado psicológicamente por la concentración de la víctima en eso que es el símbolo de su tensión extrema." (Ibidem) A continuación Bazin se refiere a este tipo de secuencia como el "análisis convencional del continuo de la realidad" (Ibidem) La tesis de Bazin es que en el cine no realista, el "análisis" de la realidad, su separación en puntos de vista que se justifican unos a otros, mediante lo que hemos llamado planos relativos, substituye a la continuidad de la realidad, que es la de un simple flujo de incidentes. En el ejemplo puesto por Bazin del close-up de la puerta de la celda girando lentamente tendríamos un caso típico del plano relativo, de lo que Bordwell llama "telos narrativo" como esencia de la escenificación fílmica. 
mostrándolo en su totalidad, excluyendo, nuevamente, como en el caso de la ley "espacial", la edición o montaje, de tal manera que se vea el evento completo, es decir, de tal manera que el plano en tanto mímesis derivada o secundaria del evento que es la mímesis primaria, nos transporte, también aquí, a las cúspides del espectáculo y, en dado caso, de la emoción cinematográfica. Vimos que al final de su examen de la secuencia de la leona y los humanos en Where no Vultures Fly, Bazin dice, "[e]l realismo reside aquí en la homogeneidad del espacio." 84 Ahora podemos complementar y decir, de acuerdo con la ley estética temporal, que justamente el realismo reside aquí en la continuidad temporal u homogeneidad del tiempo.

Bazin mismo no se refiere explícitamente a ninguna ley estética temporal, sin embargo insiste con toda claridad en lo que él considera la importancia capital, para el cine realista, aquel que da la ilusión de realidad, ${ }^{85}$ de mostrar un evento en su flujo temporal completo. Así, Bazin considera que "[e]l problema real no es la continuidad de la película expuesta sino la estructura temporal del incidente (...)" ${ }^{86}$ La "estructura temporal del incidente" remite, en primer lugar a la idea central para la concepción de Bazin acerca del realismo de que el evento sea un "incidente". Un "incidente" es algo que ocurre en una cadena de eventos pero que no está integrado en ella con la lógica de la causalidad dramática, sino que simplemente ocurre, es decir, en realidad el evento que es un “incidente" es una realidad profílmica sin ninguna teleología narrativa, está en la cadena de eventos pero también podría faltar y si es que hay una historia con una lógica causal, nada se alteraría en dicha historia. ${ }^{87}$ Por supuesto, también se puede tener una cadena no de eventos sino solamente de incidentes, es decir, de eventos que guardan coherencia entre sí pero que no están ligados causalmente - y que en ocasiones son mostrados en su

\footnotetext{
${ }^{84}$ Op. Cit. BAZIN, André. What is Cinema? Vol. 1. P. 49. Nota de pie.

${ }^{85}$ Que es muy diferente de la ilusión plástica que da una pintura, y también una simple caricatura, o de la ilusión mimética que da una actuación teatral y que también es diferente de la ilusión estética como quedó definida arriba, "aceptar que P sin creer que sea el caso que P". Por limitaciones de espacio y de consistencia temática no podemos desarrollar aquí la diferencia entre la ilusión fílmica de realidad y la ilusión estética arriba definida.

${ }^{86}$ Op. Cit. BAZIN, André. What is Cinema? Vol. 2. P. 76.

${ }^{87}$ Un ejemplo de incidente en una cadena de incidentes, lo encontramos, por ejemplo, en Ladri di Biciclette (1948) y es el plano en el que el niño Bruno examina un timbre de bicicleta en el mercado para partes de bicicletas. Dicho plano puede estar o no en la película y en términos de causalidad no se altera nada.
} 
flujo temporal en un plano continuo incluyéndolos todos ${ }^{88}$-. Adicionalmente, la "estructura temporal del incidente" remite, en segundo lugar, a que, justamente por ser un incidente, el incidente tiene que ser mostrado en su totalidad. Es decir, dado que el evento es un incidente, en otras palabras, dado que carece por completo de "teleología narrativa", el incidente importa no en relación con otros eventos sino en sí mismo y, por lo tanto tiene que ser mostrado en su totalidad. Así, según vimos en el pasaje sobre Visconti, este, dice Bazin, “(...) basa[ ] la construcción de su imagen en el evento mismo. Si un pescador enrolla un cigarrillo, no nos ahorra nada: vemos la operación completa; no resulta reducida a su significado dramático o simbólico, que es lo usual en el montaje." ${ }^{89}$

Nótese, pues, que la expresión "estructura temporal del incidente" conlleva, para la teoría de Bazin sobre el realismo cinematográfico, tanto a) que los eventos son absolutos, es decir, fuera de una lógica dramática, simples incidentes que se acumula uno tras otro, como ocurre en la vida cotidiana en su banalidad - ejemplos cumbre para Bazin Ladri di bicicletti (De Sica, 1948) y Umberto D (De Sica, 1952) - como que b) se registran y, por tanto, se muestran en su totalidad. Dejando de lado la tesis realista capital de Bazin sobre la naturaleza del plano absoluto en tanto plano que registra no "eventos" sino “incidentes", es decir sucesos sin una lógica dramática subyacente, ${ }^{90}$ nos queda la idea del

\footnotetext{
${ }^{88}$ Bazin da como ejemplo de esto un plano de Umberto D (1952): “(...) De Sica y Zavattini intentan dividir el evento en eventos más pequeños y estos en otros todavía más pequeños, hasta los límites extremos de nuestra capacidad para percibirlos en el tiempo [reconocerlos]. Así, el evento que serviría de unidad en un película clásica sería "la sirviente saliendo de la cama"; dos o tres planos cortos [planos relativos fragmentarios] hubieran sido suficientes para mostrar esto. De Sica reemplaza esta unidad narrativa con una serie de eventos 'más pequeños': ella despierta; cruza el salón; ahoga las hormigas; y así sucesivamente. Pero examinemos solamente uno de estos. Vemos cómo por su parte la molienda del café resulta dividida en una serie de momentos independientes [es la 'sumatoria' de los mismos]; por ejemplo, cuando [la joven sirviente] cierra la puerta con un toque estirando su pierna. En la medida en que la cámara se acerca a ella sigue el movimiento de su pierna de tal manera que finalmente la imagen se concentra en sus dedos sintiendo la superficie de la puerta." (Ibid., 81s.) Nótese que el plano da una secuencia de pequeños eventos que no están ligados causalmente entre si, cualquiera puede faltar y la historia de la película no se altera en su comprensión - aunque lo haga como cadena de incidentes -. Lo único que se necesita es que los incidentes guarden coherencia entre sí, lo cual está automáticamente garantizado por el plano continuo: todo lo que ahí ocurre tiene a la misma protagonista y lo que haces es coherente espacio temporalmente.

${ }^{89}$ Ibid., 43

${ }^{90}$ En nuestro amplio trabajo "Del neorrealismo fotográfico de Umberto D al hiperrealismo digital de The Adventures of Tintin. Bazin y la ontología del relato cinematográfico" (En: Op. Cit. CARRILLO CANÁN, Alberto. Fotografía, cine, juegos digitales y narratividad: estudios sobre la sensibilidad novomediática) hemos tratado con todo detalle la idea del "incidente", central en la concepción de Bazin del realismo cinematográfico y que supone que el contenido de los planos son eventos absolutos, eventos que no adquieren su sentido
} 
plano que muestra un evento en su totalidad, como en el incidente la preparación del cigarro en La terra trema o bien nuestro ejemplo del evento del salto del puente al río, el cual no es un incidente, pero sí es un evento que se muestra en su totalidad, en un plano continuo, de acuerdo con la ley estética del flujo temporal continuo definido por el evento mismo.

\section{La ilusión cinematográfica y las leyes estéticas de Bazin vs la edición}

La unión de las leyes estéticas de la homogeneidad espacial y de la continuidad temporal del evento remiten a lo que Bazin considera "restaurar a la ilusión cinematográfica una cualidad fundamental de realidad: su continuidad." ${ }^{91}$ Claramente la aplicación de ambas leyes lleva a no fraccionar el evento mediante la edición, a no separar a los participantes - como en el montaje alterno de una conversación - ni a recortar el flujo temporal del evento mostrando solamente una o varias fracciones de evento - ni siquiera suelen ser el mismo aunque se pretenda que sí, como en nuestro ejemplo del salto al río en dos planos -. Los ejemplos discutidos del plano de la leona y los humanos y del salto del puente al agua mostrando el evento completo, cumplen con los requisitos de la homogeneidad espacial y la continuidad temporal y, ciertamente, "restauran la ilusión de realidad" destruida por el montaje. Justamente este es el punto final a aclarar. Técnicamente las dos leyes demandan el plano abierto, la primera, y el plano continuo, la segunda - predominio técnico que, según vimos arriba, Bordwell rechaza -.

En el caso del plano continuo mostrando completo el salto del puente al agua, vemos el evento, registrado por la cámara, el evento mismo es solamente una escenificación, no porque no se realice sino porque se realiza para la cámara. No es un suceso real, una realidad existente en sí misma sino una actuación; no se reporta un salto ocurrido enfrente de la cámara, sino que se salta enfrente de la cámara para la cámara.

principal a partir de una teleología narrativa, como en el caso de ejemplo visto en una nota de pie anterior del close-up de la manilla de puerta de la celda del prisionero que espera al verdugo. Tal close-up, la manilla de la puerta girando lentamente, es un ejemplo claro de un evento que no es un "incidente" sino que su única justificación de ser remite a la secuencia en la que está inserto, por es un evento una teleología narrativa.

${ }^{91}$ Op. Cit. BAZIN, André. What is Cinema? Vol. 2. P. 38. 
Sabiendo que el salto es para la cámara, que no fue simplemente captado por la cámara, es decir, que no se trata de realidad sino que "solamente es cine", con base en la mímesis derivada que es el plano mostrando el salto, el espectador acepta el salto como real sabiendo que solamente es actuación, es decir, sin creer que se trate de un salto como un evento independiente del mundo. Justamente por ser una realidad profílmica el evento no es un evento del mundo en tanto tal sino parte de una ficción. Por otra parte, el salto no es mera imaginación, se le ve, se realiza. Eso que se ve, lleva, entonces, a una ilusión de realidad como estado mental.

La ilusión fílmica es justamente el correlato mental, subjetivo, de la mímesis fílmica como fenómeno tecnológico, objetivo. Es decir, la ilusión supone ver un evento - o situación - fingido como real para la cámara, y consiste en un estado mental, causado por dicha visión, estado mental que podemos definir como "aceptar el evento $E$ como habiendo ocurrido delante de la cámara sin creer que tal evento haya sido parte de los eventos del mundo", donde, obviamente, "los eventos del mundo" son los que suceden en sí mismos, por la razón que sea, pero no para la cámara, aunque se llegue a dar el caso de que se les registre fílmicamente. Nótese de pasada que quien realiza algo para filmarlo, es decir, para registrarlo, y eventualmente mostrarlo, no genera una ilusión, sino un registro, eventualmente un registro accesible a cierto público - piénsese de una acrobacia, por ejemplo -. En este caso lo que tenemos es el reporte de un evento, aunque el evento haya sido realizado para ser reportado. En este caso el evento importa antes que su reporte, a diferencia de la ficción que hemos llamado ilusión fílmica en el caso del salto mostrado en su integridad, en tanto salto no importa sino solamente en tanto salto registrado, lo cual es diferente del evento que importa tanto que se quiere registrarlo. La diferencia parece sutil pero es capital.

Supongamos ahora el evento $\mathrm{E}$ como el salto al agua de un hombre desde lo alto de un puente, lo cual es la realidad profilmica como contenido del plano mimético correspondiente, entonces tal contenido puede ser descrito por la proposición $P=$ "un hombre salta al agua desde lo alto de un puente". En la película narrativa que es el interés de Bordwell tal proposición sería parte del syuzhet y, por lo tanto, también de la fábula o 
historia. Entonces, en vez de hablar aquí de "información narrativa", como vimos que hace Bordwell, se puede hablar del estado mental de la ilusión fílmica consistente no en ver el salto en el plano, no la visión del mismo, sino en el estado mental consistente en "aceptar que $P$ sin creer que $P$ sea uno de los eventos del mundo que ocurren en sí mismos", estado mental causado por la visión del salto en el plano.

En el caso del plano abierto con la leona y los humanos teníamos el estado mental de "aceptar que $P$ sin creer que $P$ sea el caso", donde la proposición $P=$ "la leona está a punto de saltar sobre el niño". La diferencia entre ambas ilusiones es que en la de la leona y los humanos la situación es escenificada, mientras que en la ilusión del salto con ser este real no es un evento del mundo en sí mismo que, además pueda ser registrado, sino que es exclusivamente para ser registrado.

Por otra parte, en el caso de la leona y los humanos, la fragmentación en planos que hubieran evitado reunir todos los participantes en proximidad espacial, habría llevado solamente a pensar, que $P=$ "la leona está a punto de saltar sobre el niño", ya que el niño nunca habría estado cerca de la leona, y para gozar la ficción fílmica, el espectador, a pesar de no ver a los participantes en cercanía tendría que "aceptar que $P$ sin creer que sea el caso que $P^{\prime \prime}$, lo cual es la estructura de la imaginación estética. En el caso de la secuencia del salto del puente al agua desde gran altura en dos planos, el fenómeno mental básico es el del engaño o ilusión epistémica consistente en creer que hubo un salto al agua cuando este ni siquiera se realizó. En este caso la ficción narrativa parte de estado mental de un engaño, de una ilusión epistémica. Este engaño es, a su vez, la base para "aceptar el evento $E$ como habiendo ocurrido delante de la cámara sin creer que tal evento haya sido parte de los eventos del mundo", estructura que en este caso no está causada por la visión del salto al río sino por la falsa creencia en dicho salto. Esta aceptación es estética, es decir, se sabe que todo es solamente cine, que se trata de una ficción, pero tiene una estructura muy peculiar, a saber, consistente en "aceptar el salto al agua pero no se cree que el salto en el que (sí) se cree (a causa del engaño) haya sido parte de los eventos del mundo". El salto no se ve, por lo que el "aceptar que $P$ (= un hombre salta al río desde el puente) sin creer que $P$ sea el caso", es solamente 
imaginación, imaginación estética, pero en este caso una imaginación estética basada en una ilusión epistémica, es decir, en un engaño - cosa, nótese bien, imposible en la literatura, que es el ámbito más propio de la imaginación estética -.

\section{Conclusión. El plano mimético, el realismo y la ilusión}

Aun dejando del lado el problema de las inferencias tan caro a Bordwell, ya que son la parte medular de la "construcción de una historia", la simple consideración de eventos profílmicos, que realmente son registrados por la cámara, y de eventos que son una construcción mental sugerida por la edición, lleva a la conclusión de que el énfasis puesto por Bordwell en el espectador que piensa, en vez del espectador que observa, pone el acento en lo que no se ve, es decir, tal énfasis conlleva el concentrarse en la imaginación estética en detrimento de la ilusión igualmente estética. El pensar del espectador puede ser el centro de la atención de Bordwell porque él, a diferencia de Bazin, acepta sin más el hecho de la edición fílmica. Por el contrario, la tesis capital de Bazin de que “(...) el cine debería de ofrecer al espectador una ilusión tan perfecta de la realidad como sea posible dentro de (...) los límites actuales de la técnica $(\ldots)^{\prime \prime},{ }^{92}$ conlleva una crítica profunda de la edición en tanto tendencialmente destructora de la "continuidad de la realidad" y, con ello, de la ilusión fílmica para ser substituida por procesos mentales que en rigor son propios de la literatura. Por supuesto, estas ideas de Bazin conllevan, aquello a lo que Bordwell se opone y que es "privilegi[ar] ciertas técnicas", ${ }^{93}$ a saber, el plano abierto y la toma continua. En este contexto resulta plenamente comprensible que Bazin considere que la edición cinematográfica en general pueda caer con facilidad en la

\footnotetext{
92 Ibid., 26.

${ }^{93}$ Op. Cit. BORDWELL, David. Narrative in the Fiction Film. P. 26.
} 
generación de un "tiempo artificial", 94 el cual es característico en particular de la "arbitrariedad de la trama parecida a la de la película detectivesca", 95 el tipo de película que es, justamente, el género modelo para la teoría de Bordwell. ${ }^{96}$ El contraste entre Bordwell y Bazin parecería, pues, no poder ser todavía más intenso. De hecho, en el extremo, la crítica de Bazin a la edición y a favor de la ilusión cinematográfica lo lleva a postular como ideal “(...) el sueño de Zavattini de filmar ochenta minutos en la vida de un hombre sin un solo corte (...)", 97 complementariamente, Bazin nos dice también que "[e]l sueño de Zavattini es (...) el hacer una película de noventa minutos de la vida de un hombre al que nunca le sucede nada." ${ }^{98}$ En este caso la realidad profilmica sería un hombre actuando su vida durante noventa minutos, es decir, desarrollándola para la cámara. No se trataría de algo tan importante que debe ser filmado, sino justamente de algo que en una ocasión existe, ocurre, para la cámara, y con ello dicha película ideal sería la mímesis (lado objetivo) de la vida del hombre durante esos ochenta o noventa minutos, mimesis a la cual correspondería el estado mental de la ilusión fílmica de esa vida (lado subjetivo). Por supuesto, en tal caso extremo no hay ningún corte, no hay ninguna relación causal, sino solamente incidentes en el sentido definido arriba y, por lo tanto, no hay absolutamente ninguna historia por construir. La película que sería el sueño de Zavattini sería, entonces la pesadilla de Bordwell.

Finalmente diremos que en este texto nos referimos a la categoría tradicional de mímesis solamente porque es a través del rechazo de la misma que Bordwell elimina del horizonte de su teoría todo posible puente hacia la noción de ilusión estética. Sin embargo la categoría de mimesis como categoría adecuada para las artes figurativas en general, incluyendo además de la pintura el teatro, la ópera, la mímica, el cine digital, entre otras,

\footnotetext{
${ }^{94}$ Op. Cit. BAZIN, André. What is Cinema? Vol. 2. PP. 76, 65.

95 Ibid., 66.

96 Justamente Rear Window, de Hitchcock, en su calidad de película ejemplar del género detectivesco la que brinda el modelo para la teoría de Bordwell de la actividad del espectador consistente en "construir una historia". Bordwell declara que "[h]ace mucho que Rear Window (1954) ha sido usada como modelo a pequeña escala de la actividad del espectador. (...) Sin embargo Rear Window también puede ser utilizada para exhibir la complejidad completa de la actividad espectadora (...) [,], el proceso mismo del desarrollo de la acción descubre el modo en el que típicamente construimos la historia de una película de ficción." (Op. Cit. BORDWELL, David. Narrative in the Fiction Film. P. 40)

${ }^{97}$ Op. Cit. BAZIN, André. What is Cinema? Vol. 2. P. 67.

${ }^{98}$ Op. Cit. BAZIN, André. What is Cinema? Vol. 1. P. 37.
} 
es poco afortunada en el caso del cine análogo porque tal cine tiene base fotográfica y la fotografía de algo es un registro de ese algo, no es una mera representación sino, como lo examina ampliamente Bazin en su famoso ensayo La ontología de la imagen cinematográfica, ${ }^{99}$ la fotografía es una duplicación del ser de ese algo. La fotografía es, pues, registro, no mímesis, y a diferencia de la fotografía es apenas en el cine donde, según lo discutimos arriba, tenemos el registro de una mímesis, que se puede recuperar el concepto de mímesis, de fingimiento de algo. Por eso llamamos arriba al plano análogo mímesis derivada o secundaria. Sin embargo, dado que fílmicamente en general se registra directamente la apariencia de algo tal como aparece para la cámara, no como se le ve o se le imagina, como sería el caso de la pintura, la categoría más adecuada para el cine con su base fotográfica es la de realismo, tan enfatizada por Bazin, justamente reconociendo la base fotográfica, de registro, del cine análogo. Sin embargo el realismo con base en la naturaleza fotográfica del cine no son nuestro tema aquí. ${ }^{100}$ En cualquier caso, hay que conservar la idea de que la mímesis, la reproducción de la apariencia, es el lado objetivo de un fenómeno bipolar cuyo polo complementario es la ilusión estética, ya sea esta cinematográfica, tecnológicamente basada, o bien plástica o escénica, como en la pintura y el teatro respectivamente. Por ello, porque la mímesis va de la mano con la ilusión, la teoría del cine narrativo de Bordwell, al favorecer fenómenos transmiméticos, adquiere un fuerte sesgo intelectual, literario en importante medida, ajeno al de las artes plásticas y figurativas en general, incluidos el cine análogo y digital, artes que tienen como su fenómeno base el estado mental de la ilusión, no el de la generación de inferencias, estado mental propio ni siquiera de la literatura en general sino más bien de la literatura detectivesca - en la cual las inferencias retrospectivas juegan un gran papel -.

\footnotetext{
${ }^{99}$ Cfr. Op. Cit. BAZIN, André. What is Cinema? Vol. 1.

${ }^{100} \mathrm{Al}$ respecto véase nuestro trabajo "Del neorrealismo fotográfico de Umberto D al hiperrealismo digital de The Adventures of Tintin. Bazin y la ontología del relato cinematográfico". En: Op. Cit. CARRILLO CANÁN, Alberto. Fotografía, cine, juegos digitales y narratividad: estudios sobre la sensibilidad novomediática.
} 


\section{Bibliografía}

- BAZIN, André. What is Cinema? Vol. 1. California, University of California Press, 2005

- - What is Cinema? Vol. 2. California, University of California Press, 2005

- BORDWELL, David. Narrative in the Fiction Film. Madison, University of Wisconsin Press, 1985

- CARRILLO CANÁN, Alberto. Fotografía, cine, juegos digitales y narratividad: estudios sobre la sensibilidad novomediática. México, BUAP \& Itaca, 2013.

- CARRIllo CANÁN, Alberto; CALderón ZACAUla, Marco A. "La especificidad mediática de la animación". En: Reflexiones Marginales, Año 5, No. 30, 2015

- CARRILlO CANÁN, Alberto; RIVAS LÓPEZ, Víctor G. “Ilusión, emoción y sentimiento en el cine". En: Reflexiones Marginales, Año 6, No. 32, 2016

- CARRILlo CANÁN, Alberto, et. al. "Las emociones cinematográficas en Bordwell. En: Nuevo Itinerario. Revista Digital de Filosofía. Vol. 10, X, 2015

- CHATMAN, Seymour. Story and Discourse. Narrative Structure in Fiction and Film. Ithaca \& London, Cornell University Press, 1978

- DRETSKE, Fred. Knowledge and the Flow of Information. Cambridge, The MIT Press, 1982 
-

Press, 2000

- METZ, Christian. Film Language. A Semiotics of Cinema. Chicago, The University of Chicago Press, 1991 